\title{
Chemical, Functional, and Structural Properties of Spent Coffee Grounds and Coffee Silverskin
}

\author{
Lina F. Ballesteros • José A. Teixeira • Solange I. Mussatto
}

Received: 1 March 2014 / Accepted: 28 May 2014 /Published online: 20 June 2014

(C) Springer Science+Business Media New York 2014

\begin{abstract}
Spent coffee grounds (SCG) and coffee silverskin (CS) represent a great pollution hazard if discharged into the environment. Taking this fact into account, the purpose of this study was to evaluate the chemical composition, functional properties, and structural characteristics of these agroindustrial residues in order to identify the characteristics that allow their reutilization in industrial processes. According to the results, SCG and CS are both of lignocellulosic nature. Sugars polymerized to their cellulose and hemicellulose fractions correspond to 51.5 and $40.45 \% w / w$, respectively; however, the hemicellulose sugars and their composition significantly differ from one residue to another. SCG and CS particles differ in terms of morphology and crystallinity, but both materials have very low porosity and similar melting point. In terms of functional properties, SCG and CS present good water and oil holding capacities, emulsion activity and stability, and antioxidant potential, being therefore great candidates for use on food and pharmaceutical fields.
\end{abstract}

Keywords Spent coffee grounds · Coffee silverskin · Chemical composition $\cdot$ Functional properties $\cdot$ Structural characteristics

$\begin{array}{ll}\text { Abbreviations } \\ \text { CS } & \text { Coffee silverskin } \\ \text { DPPH } & \text { 2,2-diphenyl-1-picrylhydrazyl } \\ \text { DSC } & \text { Differential scanning calorimetry } \\ \text { EA } & \text { Emulsifying activity } \\ \text { ES } & \text { Emulsion stability }\end{array}$

L. F. Ballesteros $\cdot$ J. A. Teixeira $\cdot$ S. I. Mussatto $(\bowtie)$ Centre of Biological Engineering, University of Minho, Campus Gualtar, 4710-057 Braga, Portugal

e-mail: solange@deb.uminho.pt

S. I. Mussatto

e-mail: solangemussatto@hotmail.com

$\begin{array}{ll}\text { FRAP } & \text { Ferric reducing antioxidant power } \\ \text { FTIR } & \text { Fourier transform infrared spectroscopy } \\ \text { ICP-AES } & \begin{array}{l}\text { Inductively coupled plasma atomic } \\ \text { emission spectrometry }\end{array} \\ \text { IDF } & \text { Insoluble dietary fiber } \\ \text { ICDD } & \text { International Centre for Diffraction Data } \\ \text { OHC } & \text { Oil holding capacity } \\ \text { SEM } & \text { Scanning electron microscopy } \\ \text { SDF } & \text { Soluble dietary fiber } \\ \text { S } & \text { Specific surface area } \\ \text { SCG } & \text { Spent coffee grounds } \\ \text { TGA } & \text { Thermogravimetric analyses } \\ \text { TDF } & \text { Total dietary fiber } \\ \text { TE } & \text { Trolox equivalents } \\ \text { WHC } & \text { Water holding capacity } \\ \text { XRD } & \text { X-ray diffraction }\end{array}$

Introduction

Coffee is one of the most popular and appreciated beverages around the world, being consumed for its stimulating and refreshing properties, which are defined by the green beans composition and changes occurring during the roasting process (Mussatto et al. 2011a). As a consequence of this big market, the coffee industry is responsible for generating large quantities of residues; among which, spent coffee grounds (SCG) and coffee silverskin (CS) are the most significantly generated. SCG is the residual material obtained during the treatment of coffee powder with hot water or steam for the instant coffee preparation. Almost $50 \%$ of the worldwide coffee production is processed for soluble coffee preparation, which generates around 6 million tons of SCG per year (Mussatto et al. 2011a). CS is a thin tegument of the outer layer of green coffee beans obtained as a by-product of the 
roasting process (Mussatto et al. 2011a) and represents about $4.2 \%(w / w)$ of coffee beans.

In the last years, SCG and CS have attracted great attention since they are generated in large amounts every year and represent a great pollution hazard if discharged into the environment. However, as these residues are derived from coffee beans, they are expected to have properties similar to these beans and could be therefore exploited for different industrial applications. In this sense, some alternatives have been proposed to reuse these coffee residues. SCG could be used, for example, to produce fuel for industrial boilers due to its high calorific power of approximately $5,000 \mathrm{kcal} / \mathrm{kg}$ (Silva et al. 1998), as substrate for cultivation of microorganisms (Machado et al. 2012) and as raw material to produce fuel ethanol (Mussatto et al. 2012) or a distilled beverage with aroma of coffee (Sampaio et al. 2013). CS could be used as substrate for cultivation of microorganisms in order to release phenolic compounds (Machado et al. 2012) or to produce enzymes (Mussatto et al. 2013) or fructooligosaccharides (Mussatto and Teixeira 2010; Mussatto et al. 2013), or as raw material to produce fuel ethanol (Mussatto et al. 2012). In spite of these possible applications, SCG and CS are still underutilized as valuable material for industrial processes.

Nowadays, there is a great political and social pressure to reduce the pollution arising from industrial activities. For that reason, it is necessary to focus on the exploitation of SCG and $\mathrm{CS}$, and their profitable utilization, adding value to these unused materials and decreasing their impact to the environment. Despite that some characteristics of SCG and CS have been recently reported in the literature, to the best of our knowledge, there is not any study that shows a complete characterization of both materials. Such information is of great importance to identify the possible areas for application of these residues. In this sense, the purpose of the present study consisted in evaluating the chemical composition, functional properties, and structural characteristics of SCG and CS, in order to obtain more detailed information about these materials and identify potential industrial areas for their reutilization.

\section{Material and Methods}

\section{Raw Materials and Chemicals}

Spent coffee grounds (SCG) and coffee silverskin (CS), which are derived from mixtures of Arabica and Robusta coffee varieties, were provided by NovaDelta Comércio e Indústria de Cafés, S.A. (Campo Maior, Portugal). As soon as obtained, the materials were dried in an oven at $60^{\circ} \mathrm{C}$ until constant weight $(6.8 \%(w / w)$ moisture). Moisture content in the samples was measured in a moisture analyzer model MAC 50/1/ NH (Radwag, Poland). After dried, CS was milled in a Taurus mill. Then, both SCG and CS samples were sieved through a $500 \mu \mathrm{m}$ mesh screen (obtaining particles $\leq 500 \mu \mathrm{m}$ ) and stored at room temperature for further analyses. All the chemicals used were analytical grade, purchased from Sigma-Aldrich (Steinheim, Germany), Panreac Química (Barcelona, Spain), or Fisher Scientific (Leicestershire, UK). Enzymes were obtained from Sigma-Aldrich (St. Louis, MO, USA), and ultrapure water from a Milli-Q System (Millipore Inc., USA) was used.

\section{Chemical Composition Determination}

\section{Cellulose, Hemicellulose, and Lignin}

Previous cellulose, hemicellulose, and lignin determination, the extractives from SCG and CS were removed in a Soxhlet extraction system (Tecator, HT2, Netherlands) using ultrapure water and absolute ethanol as solvents in two sequential stages (Sluiter et al. 2008). The extractive free SCG and CS samples were dried at $60{ }^{\circ} \mathrm{C}$ to constant weight to be stored. To determine the cellulose, hemicellulose, and lignin (ash-free) contents, the raw material was submitted to a two-steps sequential acid hydrolysis (Sluiter et al. 2010). Sugars in the resulting solution were determined by high performance liquid chromatography (Mussatto et al. 2011b) and were used to calculate the cellulose (as glucose) and hemicellulose (as arabinose, mannose, galactose, and xylose) contents (Mussatto and Roberto 2006). The lignin (ash-free) content was also calculated as described by Mussatto and Roberto (2006).

\section{Ashes, Minerals, Fat, and Protein}

Ashes were determined by incinerating the samples at $550^{\circ} \mathrm{C}$ for $4 \mathrm{~h}$ (Horwitz and Latimer 2005). The mineral content in ashes was determined by inductively coupled plasma atomic emission spectrometry (ICP-AES), as described by Meneses et al. (2013). Fat content was determined using petroleum ether as solvent in a Soxhlet extraction system (Tecator, HT2, Netherlands) during $1 \mathrm{~h}$, according to the official AOAC method $n^{\circ} 920.39$ (Horwitz and Latimer 2005). Nitrogen was determined by combustion using a Thermo Scientific Flash 2000 Elemental Analyzer, and the protein content was estimated by using the $\mathrm{N}_{2} \times 6.25$ conversion factor.

\section{Total, Insoluble and Soluble Dietary Fibers}

The total dietary fiber (TDF) was estimated by enzymatic gravimetric method according to the official AOAC standard procedure $\mathrm{n}^{\circ} 985.29$ (Horwitz and Latimer 2005) with some modifications. Briefly, $1 \mathrm{~g}$ fat free sample was mixed with $50 \mathrm{ml}$ of phosphate buffer $(0.08 \mathrm{M}, \mathrm{pH} 6)$ in a flask. Then, 
$0.1 \mathrm{ml} \alpha$-amylase (Sigma A-3306) was added to the mixture, and the flask was covered and left during $15 \mathrm{~min}$ in a boiling water bath with discontinuous agitation. The flask was then cooled at room temperature and the $\mathrm{pH}$ of the medium was adjusted to 7.5 by adding a $0.275 \mathrm{~N} \mathrm{NaOH}$ solution. Later, $0.1 \mathrm{ml}$ protease solution (Sigma P-3910, $50 \mathrm{mg}$ in $1 \mathrm{ml}$ phosphate buffer) was added to the sample, which was covered and heated in a water bath at $60^{\circ} \mathrm{C}$ during $30 \mathrm{~min}$ with continuous agitation. After that, the sample was left at room temperature and the $\mathrm{pH}$ was adjusted to 4 by adding a $0.325 \mathrm{M}$ $\mathrm{HCl}$ solution. Additionally, $0.3 \mathrm{ml}$ amyloglucosidase (Sigma A-9913) was mixed with the sample and placed in the water bath at the same conditions used for the protease. After this process, $280 \mathrm{ml}$ of $95 \%(\mathrm{v} / \mathrm{v})$ ethanol preheated at $60^{\circ} \mathrm{C}$ was added to the sample and left at room temperature for $1 \mathrm{~h}$. The sample was filtered through filter paper and washed three times with $20 \mathrm{ml}$ of ethanol at $78 \%(v / v)$, twice with $10 \mathrm{ml}$ of ethanol at $95 \%(v / v)$, and once with $10 \mathrm{ml}$ of acetone. Finally, the filter paper containing the solid residues was dried overnight at $105^{\circ} \mathrm{C}$, and the final weight of the sample was registered. This methodology was carried out at least twice being one sample used to determine the protein content, while the other sample was employed to estimate the ashes content. Distilled water was used as blank to exclude any contribution from reagents to measurements. The TDF percentage was calculated by using the Eq 1 , where $W_{l}$ is the average weight of the sample (mg) taken, $W_{2}$ is the average final weight of the sample, $W_{3}$ and $W_{4}$ are the protein and ash weights (mg), and $W_{5}$ is the blank weight.

$\operatorname{TDF}(\%)=\left(W_{2}-W_{3}-W_{4}-W_{5}\right) * 100 / W_{1}$

Insoluble (IDF) and soluble dietary fibers (SDF) were determined using the same methodology applied for TDF determination, but without adding alcohol in the precipitation stage. The IDF percentage was calculated by Eq 1, and the SDF percentage was obtained by the difference between TDF and IDF values.

\section{Functional Properties}

\section{Water Holding Capacity and Oil Holding Capacity}

Water holding capacity (WHC) and oil holding capacity (OHC) were determined by mixing $1 \mathrm{~g}$ of sample with $10 \mathrm{ml}$ of distilled water or corn oil (Fula, Sovena Portugal; density $=0.92 \mathrm{~g} / \mathrm{ml}$ ). The mixtures were vortexed for $1 \mathrm{~min}$, centrifuged at 2,330 $\mathrm{g}$ for $30 \mathrm{~min}$, and the volume of supernatant was determined. WHC was expressed as grams of water held per grams of sample, while $\mathrm{OHC}$ was expressed as grams of oil held per grams of sample (Chau et al. 1997).

\section{Emulsifying Activity and Emulsion Stability}

Emulsifying activity (EA) and emulsion stability (ES) were determined according to Chau et al. (1997) with some modifications. Firstly, $2 \mathrm{~g}$ of sample was mixed with $100 \mathrm{ml}$ of distilled water and homogenized at 6,000 rpm for $2 \mathrm{~min}$ using an IKA T-25D Ultra-turrax homogenizer. Afterwards, $100 \mathrm{ml}$ of corn oil was added to the sample and the mixture was homogenized for $1 \mathrm{~min}$. The emulsions were centrifuged $(1,200 \mathrm{~g}$, $5 \mathrm{~min}$ ), and the emulsion volume was determined. EA (in percentage) was calculated by the ratio between the volumes of emulsified layer and the total volume used. To determine ES, the prepared emulsions were heated at $80^{\circ} \mathrm{C}$ for $30 \mathrm{~min}$, cooled at room temperature, and centrifuged $(1,200 \mathrm{~g}, 5 \mathrm{~min}$ ). ES (in percentage) was calculated by the ratio between the volumes of remaining emulsified layer and the original emulsion volume.

\section{Antioxidant Potential}

To determine the antioxidant potential, extracts were prepared by mixing $1 \mathrm{~g}$ of SCG or CS with $40 \mathrm{ml}$ of methanol at $60 \%$ $(v / v)$. The mixtures were heated during $90 \mathrm{~min}$ in a water bath at $60-65^{\circ} \mathrm{C}$ under magnetic stirring. After this time, the extracts were separated by centrifugation $(2,500 \mathrm{~g}, 20 \mathrm{~min})$, filtered through $0.22 \mu \mathrm{m}$ filters, and quantified for calculations. The antioxidant activity of the extracts was determined by two methods: the free radical scavenging activity (DPPH) assay and the ferric reducing/antioxidant power (FRAP) assay, both adapted for a 96-well microplate, as described by Martins et al. (2012). The DPPH values were expressed as micromoles of trolox equivalents (TE) per grams of dry weight material ( $\mu \mathrm{mol} \mathrm{TE} / \mathrm{g}$ ), and the FRAP values were expressed as millimoles of ferrous equivalent per grams of dry weight material (mmol Fe(II)/g).

\section{Structural Characterization}

\section{Morphology and Porosity}

Images of the SCG and CS particles were obtained by scanning electron microscopy (SEM) using an Ultra-high resolution Field Emission Gun Scanning Electron Microscope, Nova 200 Nano SEM, FEI Company. Previous to the analyses, the samples were covered with a very thin film (35 nm) of Au-Pd (80-20 wt.\%). The images were obtained by applying an acceleration voltage of $10 \mathrm{kV}$, at 200- and 2,000-fold magnifications.

The surface area and porosity of the particles were determined by $\mathrm{N}_{2}$ adsorption/desorption isotherms at $-196.15^{\circ} \mathrm{C}$ using a Quantachrome Instruments Nova 4200e analyzer, as described by Mussatto et al. (2010). The specific surface area $\left(\mathrm{S}_{\mathrm{BET}}\right)$ was determined by the BET method (Brunauer et al. 1938). Total volume of pores was calculated from the $\mathrm{N}_{2}$ adsorption isotherm at a relative pressure of 0.99 . The BJH 
method (Barrett et al. 1951) was used to evaluate the pore sizes distribution, the mesopore volume, and the specific surface area from adsorption/desorption isotherms.

\section{Thermal Behavior}

Differential scanning calorimetry (DSC) and thermogravimetric analyses (TGA) were performed in equipment Shimadzu DSC-50 and Shimadzu TGA-50 (Shimadzu Corporation, Kyoto, Japan), respectively. For the analyses, approximately $10 \mathrm{mg}$ of the sample was placed in an aluminum pan (Al crimp Pan C.201-52943) using an empty pan as reference. The measurements were carried out between 25 and $600{ }^{\circ} \mathrm{C}$ with a linear increase of $10{ }^{\circ} \mathrm{C} / \mathrm{min}$, under nitrogen atmosphere. TASYS software (Shimadzu Corporation, Kyoto, Japan) and TA Universal Analysis software (TA instruments, universal analysis 2000, USA) were used for data analysis. Enthalpy was calculated using the area of the peaks between the onset and the end set temperatures.

\section{Chemical Groups and Bonding Arrangement of Constituents}

The chemical groups and bonding arrangement of constituents present in SCG and CS structures were determined by Fourier transform infrared spectroscopy (FTIR) using a Jasco infrared spectrometer (FT/IR-4100) equipped with a diamondcomposite attenuated total reflectance (ATR) cell. The measurements were recorded with a wavenumber range from 4,000 to $600 \mathrm{~cm}^{-1}$ at a resolution of $8 \mathrm{~cm}^{-1}$ and 16 scans per sample.

\section{Crystallinity}

Crystalline phases of SGC and CS samples were evaluated by $\mathrm{X}$-ray diffraction (XRD) using a D8 Discover diffractometer (Bruker, corporation) with $\mathrm{Cu}$ tube $(\lambda=1.5406 \AA)$. The radiation was generated at $25 \mathrm{~mA}$ and $35 \mathrm{kV}$. The scattering angle of $2 \theta$ from $10^{\circ}$ to $100^{\circ}$ was measured at the step size of 0.04 and $1 \mathrm{~s}$ exposure at each step. To analyze and compare the peak positions, a cellulose spectrum from the International Centre for Diffraction Data database (ICDD card no. 00-0030226) was used.

\section{Results and Discussion}

Chemical Composition

\section{Cellulose, Hemicellulose, and Lignin}

Polysaccharides are the most abundant components in SCG and CS. In both residues, sugars are polymerized into cellulose and hemicellulose structures, which when summed correspond to 51.50 and $40.45 \%(w / w)$ of their composition on a dry weight basis (Table 1). Cellulose (as glucose) is more abundant in CS, while hemicellulose is more abundant in SCG. The hemicellulose sugars and their composition significantly differ from one residue to another. Mannose is the main sugar in SCG hemicellulose. On the other hand, xylose that is the main sugar in CS hemicellulose is not present in the SCG composition. In terms of sugars' composition, SCG is composed of $37.03 \%$ mannose, $31.90 \%$ galactose, $24.08 \%$ glucose, and $6.99 \%$ arabinose; while CS contains $58.76 \%$ glucose, $18.81 \%$ xylose, $9.29 \%$ galactose, $8.75 \%$ arabinose, and $4.37 \%$ mannose. These values are comparable to other reported in the literature for SCG and CS (Mussatto et al. 2011a, b); some differences could be attributed to the extraction process and variety of coffee beans used. Taking into account that arabinogalactans, galactomannans, and cellulose are the most abundant polysaccharides in coffee (Arya and Rao 2007); it was expected to find at least glucose, galactose, mannose, and arabinose sugars in SCG and CS composition.

Lignin is also a fraction present in a significant amount in both SCG $(23.90 \% w / w)$ and CS $(28.58 \% w / w)$ (Table 1). The lignin content in these coffee residues is higher than the values reported for other lignocellulosic materials such as brewer's spent grains (19.40\% w/w) (Meneses et al. 2013), sugarcane bagasse $(18.93 \% w / w)$ (Mesa et al. 2011), rice straw (17.20\% w/w) (Roberto et al. 2003), and barley straw $(15.50 \% w / w)$ (Sun et al. 2002). Lignin is a macromolecule

Table 1 Chemical composition of spent coffee grounds and coffee silverskin

\begin{tabular}{llc}
\hline Chemical components & \multicolumn{2}{l}{ Composition $(\mathrm{g} / 100 \mathrm{~g}$ dry material $)$} \\
\cline { 2 - 3 } & Spent coffee grounds & Coffee silverskin \\
\hline Cellulose (Glucose) & $12.40 \pm 0.79$ & $23.77 \pm 0.09$ \\
Hemicellulose & $39.10 \pm 1.94$ & $16.68 \pm 1.30$ \\
Arabinose & $3.60 \pm 0.52$ & $3.54 \pm 0.29$ \\
Mannose & $19.07 \pm 0.85$ & $1.77 \pm 0.06$ \\
Galactose & $16.43 \pm 1.66$ & $3.76 \pm 1.27$ \\
Xylose & $n d$ & $7.61 \pm 0.02$ \\
Lignin & $23.90 \pm 1.70$ & $28.58 \pm 0.46$ \\
Insoluble & $17.59 \pm 1.56$ & $20.97 \pm 0.43$ \\
Soluble & $6.31 \pm 0.37$ & $7.61 \pm 0.16$ \\
Fat & $2.29 \pm 0.30$ & $3.78 \pm 0.40$ \\
Ashes & $1.30 \pm 0.10$ & $5.36 \pm 0.20$ \\
Protein & $17.44 \pm 0.10$ & $18.69 \pm 0.10$ \\
Nitrogen & $2.79 \pm 0.10$ & $2.99 \pm 0.10$ \\
Carbon/nitrogen (C/N ratio) & $16.91 \pm 0.10$ & $14.41 \pm 0.10$ \\
Total dietary fiber & $60.46 \pm 2.19$ & $54.11 \pm 0.10$ \\
Insoluble & $50.78 \pm 1.58$ & $45.98 \pm 0.18$ \\
Soluble & $9.68 \pm 2.70$ & $8.16 \pm 0.90$ \\
\hline
\end{tabular}

Results are expressed as mean \pm standard deviation; $n=3$. $n d$ not detected 
composed of a great variety of functional groups including phenolic hydroxyl, aliphatic hydroxyl, methoxyl, carbonyl, and sulfonates, and its structure and composition vary from one raw material to another (Stewart 2008). Chlorogenic, caffeic, and coumaric acids are the most relevant lignin components in coffee and such compounds play an important role in health due to their antioxidant properties (Maydata 2002).

\section{Ashes, Minerals, Fat, and Protein}

CS has higher level of ashes $(5.36 \% \mathrm{w} / \mathrm{w})$ than SCG $(1.30 \%$ $w / w$ ) (Table 1$)$. A variety of mineral elements including potassium, calcium, magnesium, sulfur, phosphorus, iron, manganese, boron, copper, and others is present in the composition of their ashes (Table 2). Potassium is the most abundant mineral element in both SCG and CS, followed by magnesium and phosphorus in SCG and by calcium and magnesium in CS. The most important minerals present in SCG and CS are considered micronutrients essential for the human health.

Table 2 Mineral composition of spent coffee grounds and coffee silverskin

\begin{tabular}{|c|c|c|}
\hline \multirow[t]{2}{*}{ Mineral element } & \multicolumn{2}{|c|}{ Composition (mg/kg dry material) } \\
\hline & Spent coffee grounds & Coffee silverskin \\
\hline Potassium & $11,700 \pm 0.01$ & $21,100 \pm 0.00$ \\
\hline Calcium & $1,200 \pm 0.00$ & $9,400 \pm 0.01$ \\
\hline Magnesium & $1,900 \pm 0.00$ & $3,100 \pm 0.00$ \\
\hline Sulfur & $1,600 \pm 0.00$ & $2,800 \pm 0.00$ \\
\hline Phosphorus & $1,800 \pm 0.00$ & $1,200 \pm 0.00$ \\
\hline Iron & $52.00 \pm 0.50$ & $843.30 \pm 7.90$ \\
\hline Aluminum & $22.30 \pm 3.50$ & $470.60 \pm 13.9$ \\
\hline Strontium & $5.90 \pm 0.00$ & $71.72 \pm 0.30$ \\
\hline Barium & $3.46 \pm 0.05$ & $66.26 \pm 0.26$ \\
\hline Copper & $18.66 \pm 0.94$ & $63.30 \pm 1.00$ \\
\hline Sodium & $33.70 \pm 8.75$ & $57.30 \pm 1.10$ \\
\hline Manganese & $28.80 \pm 0.70$ & $50.00 \pm 0.60$ \\
\hline Boron & $8.40 \pm 1.10$ & $31.90 \pm 1.40$ \\
\hline Zinc & $8.40 \pm 0.20$ & $22.30 \pm 0.10$ \\
\hline Cobalt & $15.18 \pm 0.05$ & $21.39 \pm 1.04$ \\
\hline Iodine & $<0.10$ & $18.30 \pm 1.64$ \\
\hline Nickel & $1.23 \pm 0.59$ & $1.64 \pm 0.34$ \\
\hline Chromium & $<0.54$ & $1.59 \pm 0.00$ \\
\hline Molybdenum & $<0.08$ & $0.24 \pm 0.29$ \\
\hline Vanadium & $<0.29$ & $1.01 \pm 0.05$ \\
\hline Lead & $<1.60$ & $<1.60$ \\
\hline Selenium & $<1.60$ & $<1.60$ \\
\hline Gallium & $<1.47$ & $<1.47$ \\
\hline Tin & $<1.30$ & $<1.30$ \\
\hline Cadmium & $<0.15$ & $<0.15$ \\
\hline
\end{tabular}

Results are expressed as mean \pm standard deviation; $n=3$
They regulate multiple metabolic and physiological functions of the human body including hormonal and enzymatic activities, electrolyte balance, and normal growth (Kuan et al. 2011). These minerals also support vital processes such as respiration, digestion, and circulation. Thus, the micronutrients found in SCG and CS could be used for the production of nutrient added foods.

Low fat content is present in both residues (2.29 and $3.78 \% w / w$, for SCG and CS, respectively). Otherwise, protein is present in more significant amount in these materials (Table 1). The protein content in CS $(18.69 \% \mathrm{w} / \mathrm{w})$ is similar to the value reported by Borrelli et al. (2004) for this same material $(18.6 \% w / w)$, while the protein content in SCG $(17.44 \% w / w)$ is a little higher than the value reported by Mussatto et al. (2011b) and Ravindranath et al. (1972) for this coffee residue (about $14 \% \mathrm{w} / \mathrm{w}$ ). These differences can also be due to the conditions used for the instant coffee preparation and the variety of coffee beans used. Both SCG and CS residues are rich in polysaccharides, lignin, proteins and minerals, showing their high biotechnological value to be used, for instance, as substrates or solid supports in fermentative processes for the extraction and production of compounds with important applications in the food and pharmaceutical industries (Mussatto et al. 2011a).

\section{Total, Soluble, and Insoluble Dietary Fibers}

Dietary fiber including cellulose, hemicellulose, lignin, pectic substances, gums, and mucilages is known as the edible part of plants that is resistant to digestion and absorption in the human small intestine, with complete or partial fermentation in the large intestine (Betancur-Ancona et al. 2004). The content of total dietary fiber (TDF) in SCG $(60.46 \% w / w)$ is higher than in CS $(54.11 \% w / w)$. Additionally, insoluble dietary fiber (IDF) and soluble dietary fiber (SDF) are also present in higher amounts in SCG than in CS (Table 1). However, both residues contain similar proportion of IDF and SDF with respect to the total fiber composition, being IDF correspondent to 84 and $85 \%$ of the TDF in SCG and CS, respectively; and SDF correspondent to 16 and $15 \%$ of the TDF in SCG and CS, respectively. The IDF and SDF contents in CS are similar to the values reported by Borrelli et al. (2004) and Pourfarzad et al. (2013), who found $86 \%$ IDF and $14 \%$ SDF in the total dietary fiber $(62.2 \% \mathrm{w} / \mathrm{w})$ present in CS. The higher content of IDF than SDF in the samples is justifiable since cellulose, hemicellulose, and lignin are part of the insoluble fibers and significant amounts of these fractions are present in the composition of SCG and CS.

The SDF values in SCG and CS reveal larger soluble fiber potential of these coffee residues when compared to other materials such as Jack bean (Carnavalia ensiformis) (6.04 \%), lima bean (Phaseolus lunatus) (2.61\%) (BetancurAncona et al. 2004), rice husk (2.23\%), wheat straw (6.48\%), 
and okara (10.17\%) (Kuan and Liong 2008). It is important emphasizing that each type of fiber (insoluble and soluble) has specific properties. For instance, SDF possess large water retention, promotes the creation of bacterial flora, and decreases the absorption of fat and sugars. On the other hand, IDF has low water retention, accelerates the movement of food through the digestive system, and promotes stool regularity. SCG and CS are materials with high levels of SDF and IDF; and therefore, they have great potential to be used as raw material in the development of functional foods. In this sense, a previous study demonstrated that CS supports the growth of bifidobacteria in vitro, suggesting the possibility of producing prebiotic foods from CS (Borrelli et al. 2004).

\section{Functional Properties}

\section{Water Holding Capacity and Oil Holding Capacity}

Water holding capacity (WHC) and oil holding capacity $(\mathrm{OHC})$ are important properties to be considered in food processing. These properties can be defined as the capacity that a material has to retain water or oil after application of external centrifugal gravity force or compression. SCG has higher WHC and OHC than CS (Table 3). According to some authors, WHC and $\mathrm{OHC}$ can be related to the particle size of the material; the holding capacities being increased when smaller particle sizes are used, as a consequence of the highest packing density of smaller particles (Murthy and Naidu 2012). In the present study, particle sizes with a diameter $\leq 500 \mu \mathrm{m}$ were used because this size is considered ideal to evaluate these functional properties (Betancur-Ancona et al. 2004; Raghavendra et al. 2004) as the contact between the particle surface area and the liquid is enhanced. However, particle structure and its composition can also contribute to the overall distribution of water or oil (Robertson et al. 2000).

Table 3 Functional and physiological properties of spent coffee grounds (SCG) and coffee silverskin (CS)

\begin{tabular}{lrr}
\hline Functional and physiological properties & \multicolumn{1}{l}{ SCG } & \multicolumn{1}{l}{ CS } \\
\hline WHC (g water/g dry sample) & $5.73 \pm 0.10$ & $5.11 \pm 0.20$ \\
OHC (g oil/g dry sample) & $5.20 \pm 0.30$ & $4.72 \pm 0.10$ \\
Emulsifying activity (\%) & $54.72 \pm 0.90$ & $57.50 \pm 0.90$ \\
Emulsion stability (\%) & $92.38 \pm 0.90$ & $88.18 \pm 1.20$ \\
Antioxidant potential & & \\
$\quad$ DPPH ( $\mu$ mol TE/g dry material) & $20.04 \pm 0.05$ & $21.35 \pm 0.39$ \\
FRAP (mmol Fe(II)/g dry material) & $0.102 \pm 0.01$ & $0.045 \pm 0.01$ \\
\hline
\end{tabular}

Results are expressed as mean \pm standard deviation; $n=3$

$W H C$ water holding capacity; $O H C$ oil holding capacity; $D P P H$ antioxidant activity by the 2,2-diphenyl-1-picrylhydrazyl assay; FRAP antioxidant activity by the ferric reducing antioxidant power assay
WHC has also been reported to be higher in materials containing more elevated amounts of total dietary fiber (Raghavendra et al. 2004). This is in agreement with the results obtained in the present study, which revealed that SCG presents higher TDF (Table 1) and WHC (Table 3) than CS. In addition, SCG and CS present higher WHC than other materials such as rice husk, wheat straw, and okara (Kuan and Liong 2008), which could also be related to the presence of more fibers in SCG and CS than in these materials. The OHC has also been reported to be dependent of some properties of the material sample, including surface properties, thickness, overall charge density, and hydrophobic nature (Kuan and Liong 2008). According to some authors, lignin-richer samples present higher OHC values (Femenia et al. 1997).

The WHC and OHC results obtained for SCG and CS allow concluding that these coffee residues are materials with great swelling capacity, which is one of the most desirable parameters for the functionality of dietary fibers. WHC, for instance, has been considered an important parameter to measure the capacity can have the fibers incorporated in the diet to modify stool weight (Cummings et al. 1978). On the other hand, $\mathrm{OHC}$ is fundamental for stabilization of high-fat products and emulsions (Tiwari and Cummins 2011). Both WHC and $\mathrm{OHC}$ play an important role during preparation, processing, and storage of foods. Moreover, they can influence in the nutritional and sensory characteristics of food and its physical behavior (Tiwari and Cummins 2011).

\section{Emulsifying Activity and Emulsion Stability}

Emulsifying activity (EA) is the capacity that a compound has to form a homogenous dispersion of two immiscible liquids or emulsions, while emulsifying stability (ES) is the effectiveness of a molecule to maintain a thermodynamically stable emulsion (Sánchez-Zapata et al. 2009). SCG and CS have similar values of EA (54.72 and $57.50 \%$, respectively), while ES is slightly higher in SCG than in CS (92.38 and $88.18 \%$, respectively) (Table 3 ). Both coffee residues present higher ES values than others materials such as lima bean $(28.25 \%)$ (Betancur-Ancona et al. 2004), papaya kernel flour (58 \%), corncobs $(80 \%)$, and wheat straw $(86.94 \%$ ) (Kuan et al. 2011). This behavior is directly related to the type of fiber and the percentage of soluble and insoluble fibers in the material composition. Moreover, the protein fraction present in the residues plays also an important role in anchoring the moiety of fiber to the oil or water interface (Kuan and Liong 2008).

SCG and CS are then materials with excellent emulsifying activity and emulsion stability, and present therefore great potential to be used as emulsifiers in different food products including beverages, dairy, baking, confectioneries, or in products for animal nutrition, which require long emulsion stability. 


\section{Antioxidant Potential}

In order to evaluate the antioxidant activity of SCG and CS, extracts were produced by solid-liquid extraction using methanol, which has been considered one of the best solvents to extract antioxidant compounds from natural sources duo its polarity, viscosity, and ability to promote high extraction yields (Mussatto et al. 2011c). According to the results, SCG and CS have similar antioxidant potential (20.04 and $21.35 \mu \mathrm{mol} \mathrm{TE} / \mathrm{g}$ dry material, respectively) when analyzed by the DDPH assay. However, the FRAP assay revealed a 2.3fold higher antioxidant potential for SCG when compared to CS (Table 3). According to the current literature, different methods can be used to evaluate the antioxidant activity in food and biological systems. However, as each method is based on a different reaction, it is strongly advisable determining the antioxidant potential of a sample by different methods in order to better interpret the results. Such a fact was demonstrated in the present study since the DPPH assay was not able to detect significant differences in the antioxidant potential of the samples, while the FRAP assay was.

Antioxidant compounds have numerous applications in food, cosmetic, and pharmaceutical areas, because they can protect against chronic and degenerative diseases such as cancer and diabetes mellitus, and decrease the risk factors of cardiovascular diseases, among others (Ao et al. 2011). These results suggest the possibility of reusing both coffee residues (mainly SCG) to obtain such compounds.

\section{Structural Characterization}

\section{Morphology and Porosity}

Images obtained by scanning electron microscopy revealed significant morphological differences between SCG and CS. CS particles (Fig. 1c, d) present denser morphology than SCG particles (Fig. 1a, b) and are composed of thin sheets of material that resembles sawdust. In terms of porosity, the $\mathrm{N}_{2}$ adsorption/desorption isotherms revealed that SCG has higher porosity than CS (Fig. 2a). However, the amount of $\mathrm{N}_{2}$ adsorbed by both the samples was very low, suggesting that they have poorly developed mesoporosity. It was also verified the absence of micropores in the samples since microporous materials present $\mathrm{N}_{2}$ adsorption/desorption isotherms with tendency to form a plateau at low relative pressures (Mussatto et al. 2010), which was not verified in the present study for any of the cases. Similar conclusions were obtained by the BET surface area $\left(\mathrm{S}_{\mathrm{BET}}\right)$ results, which revealed that SCG has higher $\mathrm{S}_{\mathrm{BET}}\left(4.3 \mathrm{~m}^{2} / \mathrm{g}\right)$ than CS $\left(2.1 \mathrm{~m}^{2} / \mathrm{g}\right)$, but the $\mathrm{S}_{\mathrm{BET}}$ was very low for both the samples, and micropores were not detected in any of them. The total volume of pores was also very close for both residues $\left(0.004\right.$ and $0.003 \mathrm{~cm}^{3} / \mathrm{g}$ for SCG and CS, respectively).

Analyses of the mesopore size distribution by the BJH method (Fig. 2b) showed a well-defined profile for both samples with most of the mesopores at around 3 and $12 \mathrm{~nm}$ ( $r=10$ and $60 \AA$, respectively), and a non-significant amount of mesopores larger than $18 \mathrm{~nm}$. These analyses confirm that SCG and CS are materials with very low porosity, containing mesopores with less than $12 \mathrm{~nm}$, specific surface areas between 2 and $5 \mathrm{~m}^{2} / \mathrm{g}$, and specific pore volumes between 0.003 and $0.004 \mathrm{~cm}^{3} / \mathrm{g}$. The low porosity of these materials can be advantageous depending on the final application. On the other hand, when materials with higher porosity are desired, an alternative to improve the porosity of SCG and CS would be submitting these materials to any treatment in order to promote a total or partial degradation of the cellulose-lignin matrix, which would decrease their crystallinity increasing the porosity as a consequence.

\section{Thermal Behavior}

The DSC thermogram (Fig. 3a) shows the thermal transitions of the samples between 25 and $600{ }^{\circ} \mathrm{C}$ obtained at a heating rate of $10^{\circ} \mathrm{C} / \mathrm{min}$ under a constant nitrogen atmosphere. The thermograms obtained for SCG and CS exhibited two events:
Fig. 1 Micrographs by scanning electron microscopy (SEM) of spent coffee grounds and coffee silverskin particles.

Magnification, 200-fold (a, c) and 2,000-fold (b, d)

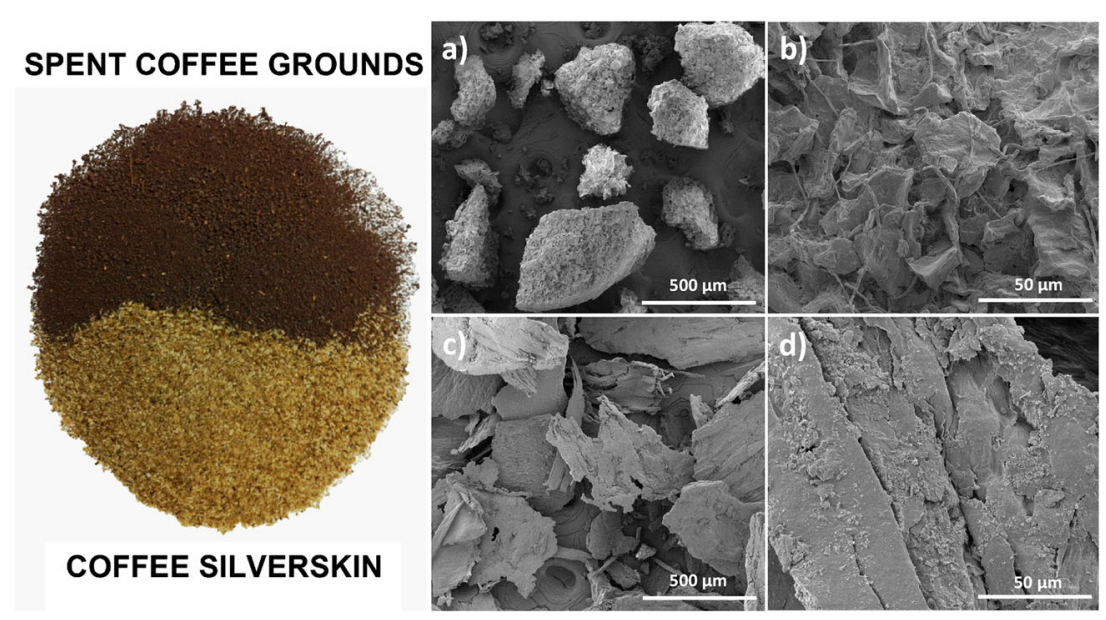


a)

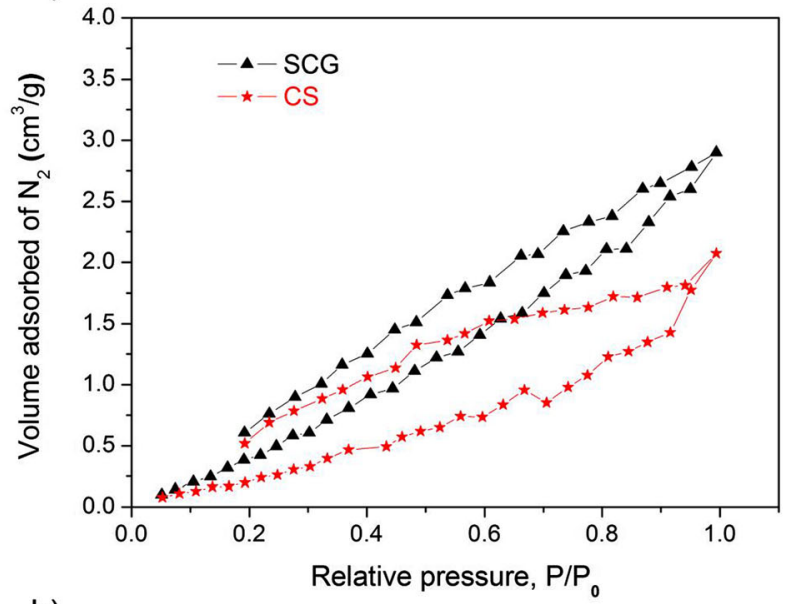

b)

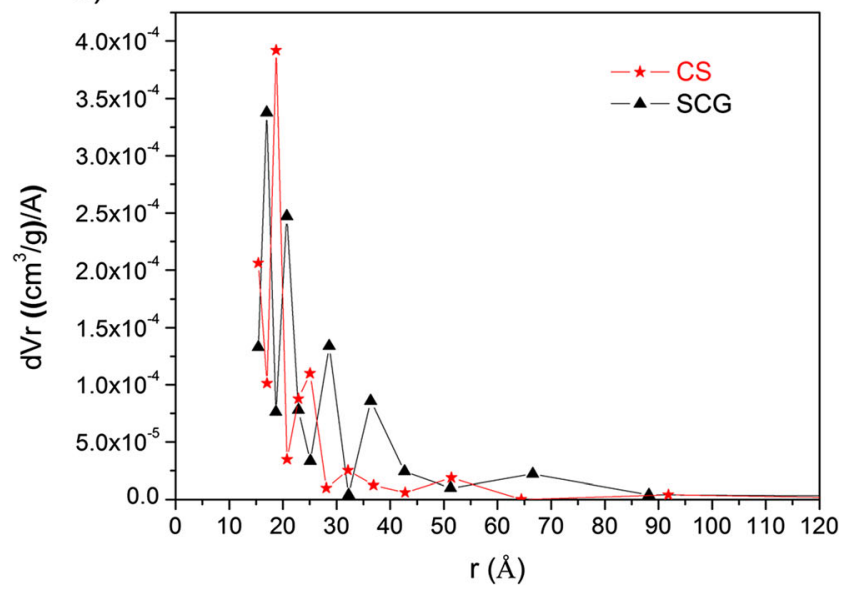

Fig. $2 \mathrm{~N}_{2}$ adsorption/desorption isotherms at $-196.15^{\circ} \mathrm{C}$ (a) volume adsorbed of $\mathrm{N}_{2}$ as a function of the relative pressure for spent coffee grounds (SCG) and coffee silverskin (CS). Pores size distribution by the $\mathrm{BJH}$ method (b) the derivative of the desorbed volume as a function of the pore radius, which represents the change of volume desorbed by SCG and $\mathrm{CS}$ in a pore size range. Standard deviation values were less than $2.5 \%$ in all cases

an initial endothermic phase followed by an exothermic phase. For both SCG and CS, an early endothermic event was observed with a peak at 76.89 and $74.60{ }^{\circ} \mathrm{C}$, respectively, and an associated enthalpy change of 192.80 and $102.80 \mathrm{~J} / \mathrm{g}$. This event is related to the melting transition that occurs over a range of temperature due to the presence of impurities in the samples, the vaporization of water (indicating the presence of hydrophilic groups) and the crystalline nature of the materials. This first event allows concluding that SCG and CS have similar melting point at 76.89 and $74.60{ }^{\circ} \mathrm{C}$, respectively. The second event corresponds to an exothermic transition and was observed at 303.00 and $317.70^{\circ} \mathrm{C}$ for SCG and CS, respectively, with an associated enthalpy change of 68.38 and $7.75 \mathrm{~J} / \mathrm{g}$. This transition is related to the thermal depolymerisation and branching of the samples, occurring at temperature ranges varying between 220 and $310^{\circ} \mathrm{C}$ (Sperling 2006).
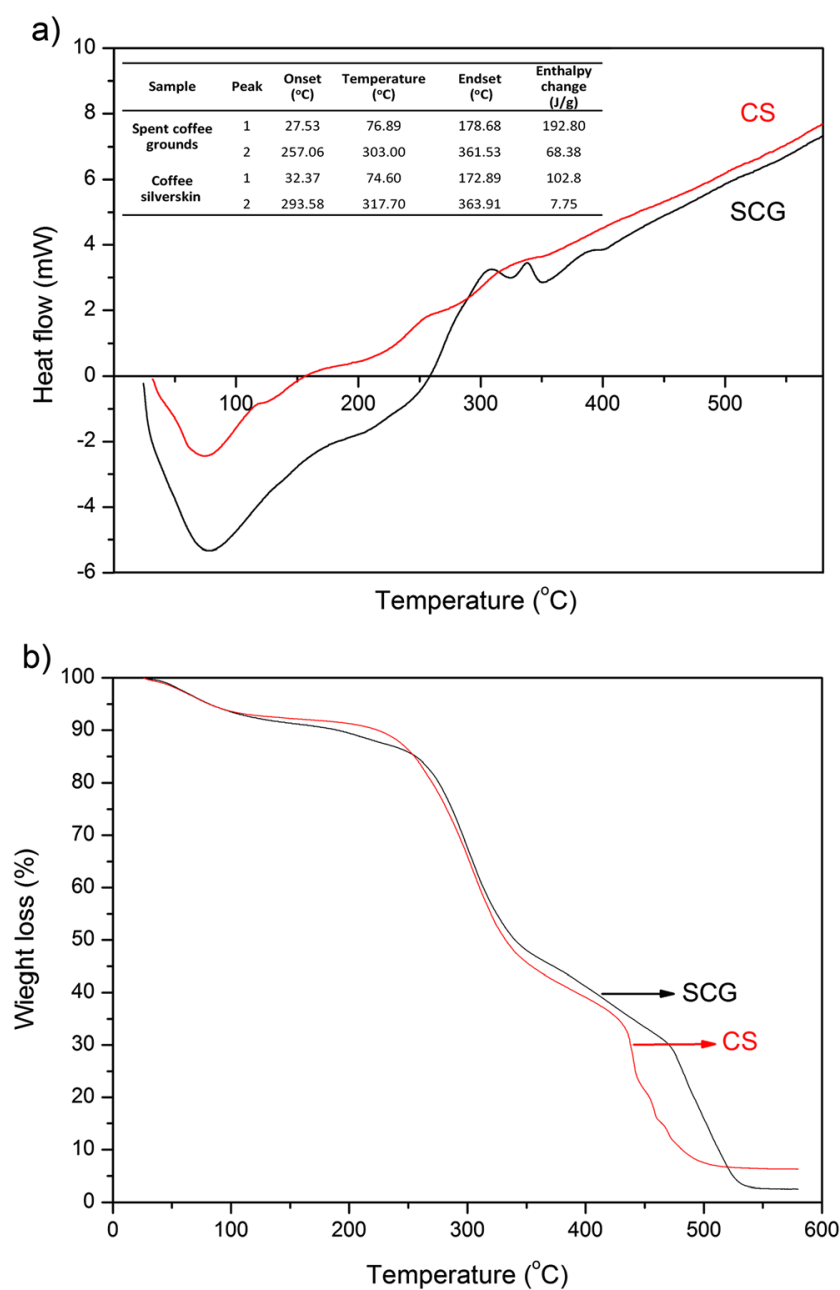

Fig. 3 DSC (a) and TGA (b) curves obtained for spent coffee grounds (SCG) and coffee silverskin (CS)

The TGA curves (Fig. 3b) show the weight losses of the samples when exposed to heating until $600{ }^{\circ} \mathrm{C}$. SCG and CS present similar TGA curves with three defined mass loss stages. The first one starts at approximately 60.60 and $61.58^{\circ} \mathrm{C}$, and corresponds to soft weight losses of about 7.77 and $6.80 \%$ for SCG and CS, respectively, as a result of the water evaporation (dehydration of the sample). The greatest transformation and mass losses occur during the second stage, at approximately $300^{\circ} \mathrm{C}$. At this stage, the depolymerization and decomposition of polysaccharides and some oils present in the sample occurs, providing weight losses of 43.50 and $48.01 \%$ for SCG and CS, respectively. Finally, the third and last thermal stage related to the decomposition of the samples starts at $499.29^{\circ} \mathrm{C}$ for SCG and at $457.24^{\circ} \mathrm{C}$ for CS, and results in weight losses of 33.08 and $34.17 \%$, respectively.

\section{Chemical Groups and Bonding Arrangement of Constituents}

FTIR analyses (Fig. 4a) revealed that SCG and CS have absorption bands typical of lignocellulosic materials, although 


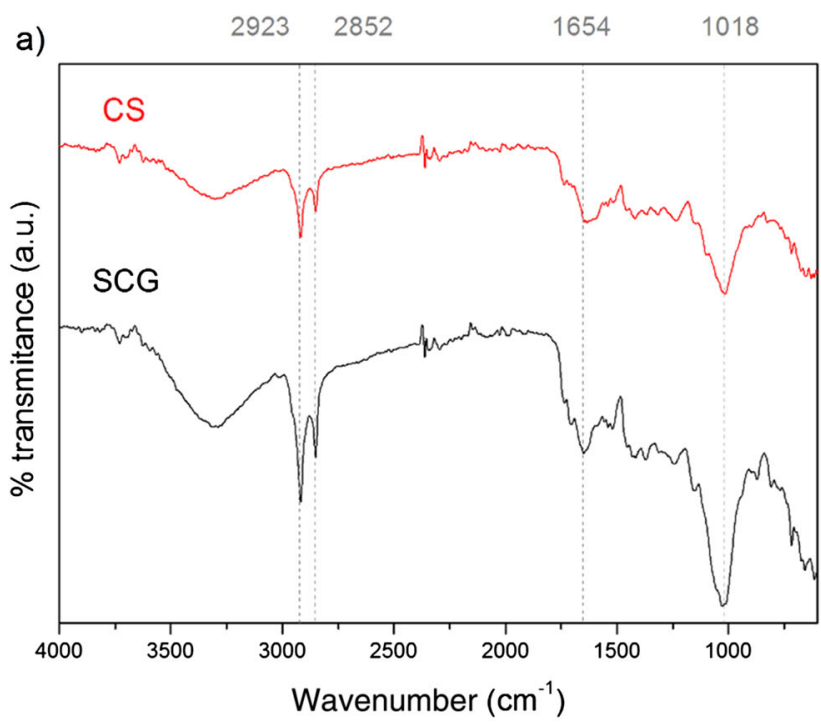

b)

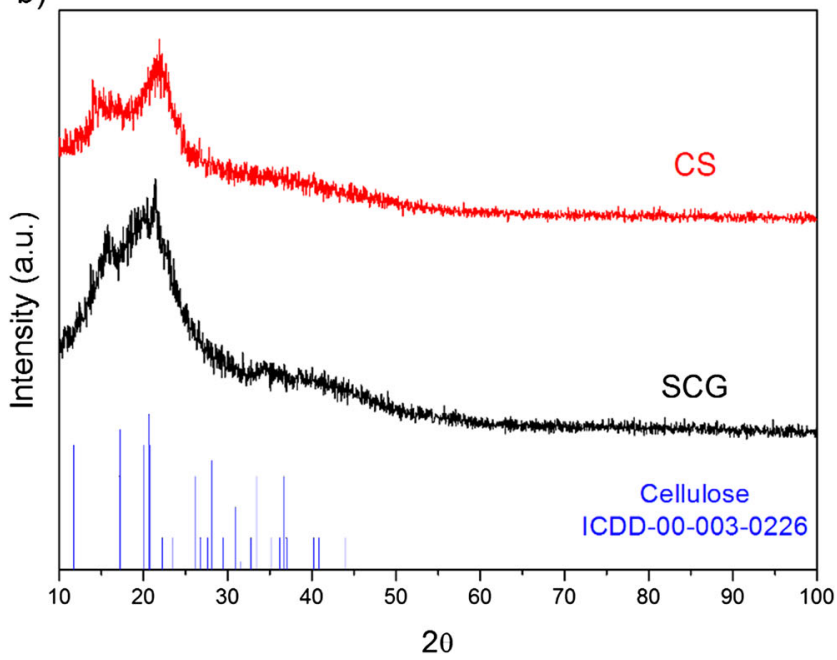

Fig. 4 FTIR spectra (a) and XRD diffractograms (b) obtained for spent coffee grounds (SCG) and coffee silverskin (CS). Cellulose peak positions indicated as reference in the XRD diffractograms were obtained from the International Centre for Diffraction Data (ICDD) database (ICDD card no. 00-003-0226)

the magnitude of these bands differs to each residue. The broad peak between 3,600 and $3,200 \mathrm{~cm}^{-1}$ is related to the hydroxyl group of $\mathrm{O}-\mathrm{H}$ stretching vibration. The region between 3,000 and $2,800 \mathrm{~cm}^{-1}$ with two sharp bands at 2,923 and $2,852 \mathrm{~cm}^{-1}$ are attributed to $\mathrm{C}-\mathrm{H}$ stretching vibration. These bands have been previously reported in spectra of roasted Arabica and Robusta coffee samples (Kemsley et al. 1995) and roasted coffee husks (Reis et al. 2013). Moreover, studies of FTIR analysis from caffeinated beverages such as tea, coffee, and soft drinks have reported peaks at this same region $\left(2,882\right.$ and $\left.2,829 \mathrm{~cm}^{-1}\right)$, which are related to the asymmetric stretching of $\mathrm{C}-\mathrm{H}$ bonds of methyl $\left(-\mathrm{CH}_{3}\right)$ group in the caffeine molecule and can be successfully used to develop predictive models for quantitative analysis of caffeine (Paradkar and Irudayaraj 2002). The band between 1,700 and
$1,600 \mathrm{~cm}^{-1}$ is highly associated with chlorogenic acids and caffeine (Ribeiro et al. 2010). Then, the peak at $1,654 \mathrm{~cm}^{-1}$ can be attributed to the absorption of these compounds, being the peak more intense when their concentration in the sample increases. The broad band between 1,135 and $952 \mathrm{~cm}^{-1}$ results from the stretching vibration of $\mathrm{C}-\mathrm{O}$ in $\mathrm{C}-\mathrm{O}-\mathrm{H}$ bonds such as glycosidic bonds and are related to galactomannans polysaccharide' sugars (Figueiró et al. 2004).

\section{Crystallinity}

In order to evaluate and compare the crystallinity of the coffee residues, a cellulose spectrum taken from the International Centre for Diffraction Data (ICDD) database was used as a reference. As can be seen in Fig. 4b, SCG and CS present similar XRD spectra, which, when compared to the cellulose spectrum used as reference, indicate the existence of crystalline regions in the structure of both coffee residues. The cellulose molecule is known to have crystalline and amorphous regions. Crystalline regions are mostly responsible by a high tensile strength and represent cellulose less accessible to chemical attacks due to hydrogen strong interactions between the microfibers (Ragauskas and Huang 2013). In contrast, hemicellulose and other constituents of SCG and CS exhibit an amorphous structure more easily degradable and susceptible to chemical attacks.

Although CS contains higher cellulose content than SCG (Table 1), the XRD spectra reveal that SCG is more crystalline than CS, suggesting the important differences in the cellulosic structure of both materials. According to some authors, the thermal treatment by which the coffee beans are subjected could be responsible for at least a part of the crystallinity observed in SCG structure since this process promotes the elimination of some water molecules incorporated into the crystal fraction, transforming some $\alpha$-polymorph to $\beta$ crystal phase structures (Rivera et al. 2011).

\section{Conclusions}

This study allows concluding that SCG and CS are sugar-rich lignocellulosic materials composed also of high levels of insoluble, soluble, and total dietary fibers. Both residues have interesting functional properties including water holding capacity, oil holding capacity, emulsion activity and stability, and antioxidant potential, which open up possibilities for their reutilization in different biotechnological process. They could be used, for example, as preservatives in food formulations, as natural antioxidant sources for application in food and pharmaceutical products, or as raw material to obtain new functional ingredients for food industry. SCG and CS are also thermostable in a large range of temperature, being therefore 
suitable for application in the manufacture of biomaterials and encapsulation products for several industrial purposes. In brief, the present study allows concluding that SCG and CS have characteristics that make possible their reutilization in different industrial fields. Despite some efforts have recently been done in order to find possible alternatives to reuse these residues, the implementation of industrial processes using SCG or CS as raw material is still a challenge to be surpassed. This study gives support to direct further research and developments in this area.

Acknowledgements The authors acknowledge the financial support of the Science and Technology Foundation of Portugal (FCT) through the grant SFRH/BD/80948/2011 and the Strategic Project PEst-OE/EQB/ LA0023/2013. The authors also thank the Project "BioInd - Biotechnology and Bioengineering for improved Industrial and Agro-Food processes", REF. NORTE-07-0124-FEDER-000028 co-funded by the Programa Operacional Regional do Norte (ON.2-O Novo Norte), QREN, FEDER. Thanks are also given to Prof. José J.M. Órfão, from the Department of Chemical Engineering, Universidade do Porto (Portugal), for his assistance with the porosity analyses.

\section{References}

Ao, C., Higa, T., Khanh, T. D., Upadhyay, A., \& Tawata, S. (2011). Antioxidant phenolic compounds from Smilax sebeana Miq. $L W T$ Food Science and Technology, 44(7), 1681-1686.

Arya, M., \& Rao, L. J. M. (2007). An impression of coffee carbohydrates. Critical Reviews in Food Science and Nutrition, 47(1), 51-67.

Barrett, E. P., Joyner, L. G., \& Halenda, P. P. (1951). The determination of pore volume and area distributions in porous substances. I. Computations from nitrogen isotherms. Journal of the American Chemical Society, 73(1), 373-380.

Betancur-Ancona, D., Peraza-Mercado, G., Moguel-Ordoñez, Y., \& Fuertes-Blanco, S. (2004). Physicochemical characterization of lima bean (Phaseolus lunatus) and Jack bean (Canavalia ensiformis) fibrous residues. Food Chemistry, 84(2), 287-295.

Borrelli, R. C., Esposito, F., Napolitano, A., Ritieni, A., \& Fogliano, V. (2004). Characterization of a new potential functional ingredient: Coffee silverskin. Journal of Agricultural and Food Chemistry, 52(5), 1338-1343.

Brunauer, S., Emmett, P. H., \& Teller, E. (1938). Adsorption of gases in multimolecular layers. Journal of the American Chemical Society, 60(2), 309-319.

Chau, C.-F., Cheung, P. C. K., \& Wong, Y.-S. (1997). Functional properties of protein concentrates from three Chinese indigenous legume seeds. Journal of Agricultural and Food Chemistry, 45(7), 2500-2503.

Cummings, J. H., Branch, W., Jenkins, D. J. A., Southgate, D. A. T., Houston, H., \& James, W. P. T. (1978). Colonic response to dietary fiber from carrot, cabbage, apple, bran, and guar gum. The Lancet, 1(8054), 5-9.

Femenia, A., Lefebvre, A.-C., Thebaudin, J.-Y., Robertson, J. A., \& Bourgeois, C.-M. (1997). Physical and sensory properties of model foods supplemented with cauliflower fiber. Journal of Food Science, 62(4), 635-639.

Figueiró, S. D., Góes, J. C., Moreira, R. A., \& Sombra, A. S. B. (2004). On the physic-chemical and dieletric properties of glutaraldehyde crosslinked galactomannan-Collagen films. Carbohydrate Polymers, 56(3), 313-320.
Horwitz, W., \& Latimer, G. W., Jr. (2005). Official methods of analysis of AOAC International (18th ed.). Gaithersburg, Maryland, USA: AOAC International.

Kemsley, E. K., Ruault, S., \& Wilson, R. H. (1995). Discrimination between Coffea arabica and Coffea canephora variant robusta beans using infrared spectroscopy. Food Chemistry, 54(3), 321-326.

Kuan, Y.-H., \& Liong, M.-T. (2008). Chemical and physicochemical characterization of agrowaste fibrous materials and residues. Journal of Agricultural and Food Chemistry, 56(19), 9252-9257.

Kuan, C.-Y., Yuen, K.-H., Bhat, R., \& Liong, M.-T. (2011). Physicochemical characterization of alkali treated fractions from corncob and wheat straw and the production of nanofibres. Food Research International, 44(9), 2822-2829.

Machado, E. M. S., Rodriguez-Jasso, R. M., Teixeira, J. A., \& Mussatto, S. I. (2012). Growth of fungal strains on coffee industry residues with removal of polyphenolic compounds. Biochemical Engineering Journal, 60, 87-90.

Martins, S., Aguilar, C. N., Teixeira, J. A., \& Mussatto, S. I. (2012). Bioactive compounds (phytoestrogens) recovery from Larrea tridentata leaves by solvents extraction. Separation and Purification Technology, 88, 163-167.

Maydata, A. G. (2002). Café, antioxidantes y protección a la salud. Medisan, 6(4), 72-81.

Meneses, N. G. T., Martins, S., Teixeira, J. A., \& Mussatto, S. I. (2013). Influence of extraction solvents on the recovery of antioxidant phenolic compounds from brewer's spent grains. Separation and Purification Technology, 108, 152-158.

Mesa, L., González, E., Cara, C., González, M., Castro, E., \& Mussatto, S. I. (2011). The effect of organosolv pretreatment variables on enzymatic hydrolysis of sugarcane bagasse. Chemical Engineering Journal, 168(3), 1157-1162.

Murthy, P. S., \& Naidu, M. M. (2012). Recovery of phenolic antioxidants and functional compounds from coffee industry by-products. Food and Bioprocess Technology, 5(3), 897-903.

Mussatto, S. I., Ballesteros, L. F., Martins, S., Maltos, D. A. F., Aguilar, C. N., \& Teixeira, J. A. (2013). Maximization of fructooligosaccharides and $\beta$-fructofuranosidase production by Aspergillus japonicus under solid-state fermentation conditions. Food and Bioprocess Technology, 6(8), 2128-2134.

Mussatto, S. I., Ballesteros, L. F., Martins, S., \& Teixeira, J. A. (2011a). Extraction of antioxidant phenolic compounds from spent coffee grounds. Separation and Purification Technology, 83, 173-179.

Mussatto, S. I., Carneiro, L. M., Silva, J. P. A., Roberto, I. C., \& Teixeira, J. A. (2011b). A study on chemical constituents and sugars extraction from spent coffee grounds. Carbohydrate Polymers, 83(2), 368-374.

Mussatto, S. I., Fernandes, M., Rocha, G. J. M., Órfão, J. J. M., Teixeira, J. A., \& Roberto, I. C. (2010). Production, characterization and application of activated carbon from brewer's spent grain lignin. Bioresource Technology, 101(7), 2450-2457.

Mussatto, S. I., Machado, E. M. S., Carneiro, L. M., \& Teixeira, J. A. (2012). Sugars metabolism and ethanol production by different yeast strains from coffee industry wastes hydrolysates. Applied Energy, 92, 763-768.

Mussatto, S. I., Machado, E. M. S., Martins, S., \& Teixeira, J. A. (2011c). Production, composition, and application of coffee and its industrial residues. Food and Bioprocess Technology, 4(5), 661-672.

Mussatto, S. I., \& Roberto, I. C. (2006). Chemical characterization and liberation of pentose sugars from brewer's spent grain. Journal of Chemical Technology \& Biotechnology, 81(3), 268-274.

Mussatto, S. I., \& Teixeira, J. A. (2010). Increase in the fructooligosaccharides yield and productivity by solid-state fermentation with Aspergillus japonicus using agro-industrial residues as support and nutrient source. Biochemical Engineering Journal, 53(1), 154-157. 
Paradkar, M. M., \& Irudayaraj, J. (2002). Rapid determination of caffeine content in soft drinks using FTIR-ATR spectroscopy. Food Chemistry, 78(2), 261-266.

Pourfarzad, A., Mahdavian-Mehr, H., \& Sedaghat, N. (2013). Coffee silverskin as a source of dietary fiber in bread-making: Optimization of chemical treatment using response surface methodology. LWT - Food Science and Technology, 50(2), 599-606.

Ragauskas, A. J., \& Huang, F. (2013). Chemical pretreatment techniques for biofuels and biorefineries from softwood. In Z. Fang (Ed.), Pretreatment techniques for biofuels and biorefineries. Berlin: Springer.

Raghavendra, S. N., Rastogi, N. K., Raghavarao, K. S. M. S., \& Tharanathan, R. N. (2004). Dietary fiber from coconut residue: Effects of different treatments and particle size on the hydration properties. European Food Research and Technology, 218(6), 563-567.

Ravindranath, R., Yousuf Ali Khan, R., Oby Reddy, T., Thirumala Rao, S. D., \& Reddy, B. R. (1972). Composition and characteristics of Indian coffee bean, spent ground and oil. Journal of the Science of Food and Agriculture, 23(3), 307-310.

Reis, N., Franca, A. S., \& Oliveira, L. S. (2013). Discrimination between roasted coffee, roasted corn and coffee husks by Diffuse Reflectance Infrared Fourier Transform Spectroscopy. LWT - Food Science and Technology, 50(2), 715-722.

Ribeiro, J. S., Salva, T. J., \& Ferreira, M. M. C. (2010). Chemometric studies for quality control of processed Brazilian coffees using DRIFTS. Journal of Food Quality, 33(2), 212-227.

Rivera, W., Velasco, X., Gálvez, C., Rincón, C., Rosales, A., \& Arango, P. (2011). Effect of the roasting process on glass transition and phase transition of Colombian Arabic coffee beans. Procedia Food Science, 1, 385-390.

Roberto, I. C., Mussatto, S. I., \& Rodrigues, R. C. L. B. (2003). Dilute-acid hydrolysis for optimization of xylose recovery from rice straw in a semi-pilot reactor. Industrial Crops and Products, 17(3), 171-176.
Robertson, J. A., Monredon, F. D., Dysseler, P., Guillon, F., Amado, R., \& Thibault, J. F. (2000). LWT - Food Science and Technology, 33(2), $72-79$.

Sampaio, A., Dragone, G., Vilanova, M., Oliveira, J. M., Teixeira, J. A., \& Mussatto, S. I. (2013). Production, chemical characterization, and sensory profile of a novel spirit elaborated from spent coffee ground. LWT - Food Science and Technology, 54(2), 557-563.

Sánchez-Zapata, E., Fuentes-Zaragoza, E., Fernández-López, J., Sendra, E., Sayas, E., Navarro, C., \& Pérez-Álvarez, J. A. (2009). Preparation of dietary fiber powder from tiger nut (Cyperus esculentus) milk ("Horchata") byproducts and its physicochemical properties. Journal of Agricultural and Food Chemistry, 57(17), 7719-7725.

Silva, M. A., Nebra, S. A., Machado Silva, M. J., \& Sanchez, C. G. (1998). The use of biomass residues in the Brazilian soluble coffee industry. Biomass and Bioenergy, 14(5-6), 457-467.

Sluiter, A., Hames, B., Ruiz, R., Scarlata, C., Sluiter, J., Templeton, D., \& Crocker, D. (2010). Determination of structural carbohydrates and lignin in biomass. Technical Report NREL/TP-510-42618.

Sluiter, A., Ruiz, R., Scarlata, C., Sluiter, J., \& Templeton, D. (2008). Determination of extractives in biomass. Technical Report NREL/TP-510-42619.

Sperling, L. H. (2006). Introduction to physical polymer science (4th ed.). New Jersey: Wiley.

Stewart, D. (2008). Lignin as a base material for materials applications: Chemistry, application and economics. Industrial Crops and Products, 27(2), 202-207.

Sun, R. C., Sun, X. F., Fowler, P., \& Tomkinson, J. (2002). Structural and physico-chemical characterization of lignins solubilized during alkaline peroxide treatment of barley straw. European Polymer Journal, 38(7), 1399-1407.

Tiwari, U., \& Cummins, E. (2011). Pulse foods: Processing, quality and nutraceutical applications (pp. 121-156). San Diego: Academic. 